\title{
Vocational Teacher Educators' Role Identity: A Case Study in Malta
}

\author{
Alison Said \\ Lancaster University, UK
}

DOI: https://doi.org/10.18778/1733-8077.18.1.03

Keywords:

Vocational Teacher Educators (VTEs); Role Identities; Vocational Education (VET) Context; Identity Theory

\begin{abstract}
This paper gains a deeper understanding of the professional role identities of vocational teacher educators (VTEs) when compared with mainstream teacher educators (MTEs) in Malta. It is framed using identity theory from the structural symbolic interactionism perspective (Burke and Stets 2009). Data were collected through semi-structured interviews, adopting thematic analysis. Findings show that VTEs and MTEs underpin their teaching differently, influenced by the perceptions they have about their professional role identities. There is no "one size fits all" solution for each country, yet this study contributes to a field with a limited research base and offers new insights to identity theory.
\end{abstract}

Alison Said is a warranted engineer by profession who worked in Malta's telecommunications industry before her current senior lecturing role within Malta's main vocational education and training institution, MCAST. She received her B.Sc. (Hons.) ICT in Communications and Computer Engineering and M.Sc. ICT in Telecommunications from the University of Malta in 2010 and 2012, respectively. In 2020, she was awarded a Ph.D. in Higher Education: Research, Evaluation and Enhancement by Lancaster University. Her doctoral research was partially funded by the Tertiary Education Scholarship Scheme (TESS) Grant offered by the Maltese Ministry for Education and Employment, which she had won in 2018. Her main research interests focus on vocational teaching and learning, higher education, and professional identities.

email address: a.said@lancaster.ac.uk, dringas20@gmail.com

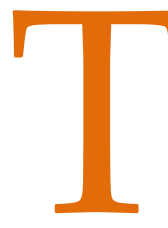

hose who support future teachers, teacher educators (TEs), play a significant role in initial teacher education (ITE) programs and the continuous professional development (CPD) of all teachers from across the entire state and private education sectors. An ITE program, which is a pre-service teaching program, is the entry point into the teaching profession, where student teachers study a combination of both theoretical and practical subject areas. Such courses are provided by TEs, who are "at the core of good teacher education" (Vloet and van Swet 2010:149). According to Loughran (2006), their work significantly impacts the quality of future classroom teachers. As a result, attention has increased on these key actors within the education sector. Research has focused 
on their roles and identities, the challenges they face, and the support they receive (Cochran-Smith 2003; Murray and Male 2005; Lunenberg, Korthagen, and Swennen 2007; Kosnik and Beck 2008; Murray, Swennen, and Shagrir 2008).

Nonetheless, although research has increased in this area, more needs to be understood about TEs, their different roles, and their professional development needs concerning their practice (Izadinia 2014). Not recognizing the importance and significance of their profession will heavily impact the formation of their role identities, which is a crucial aspect for them personally and for the service they deliver (Lunenberg and Hamilton 2008).

The European Commission (EC) (2013) admits that most European Union (EU) countries still do not share an understanding of TEs' roles, competencies, or qualification requirements,

in most member states, government policy on the quality requirements for teacher educators, or on their academic and professional development, does not exist or is underdeveloped; this is especially the case for those who educate teachers in early education, adult education, as well as vocational education and training. [p. 7]

The situation affects the educational attainment of the competencies TEs need to fulfill roles effectively. Thus, policies need to be established to support the profession and guarantee consistency and quality.

Professional role identities have common aims, values, and philosophy (EC 2013) and are important in any professional context. In addition, the quality of the professional role also determines members' standards (EC 2013). Research by Swennen, Jones, and Volman (2010) found that TEs have multiple pro- fessional identities as classroom teachers, teachers in higher education (HE), researchers, or teachers of teachers. It is also important to look at the individual personal and social manifestations of a particular professional identity.

Research has mainly focused on TEs within mainstream education $^{1}$ (Bullough 2005), where they are considered to be a "poorly understood occupational group" (Davison, Murray, and John 2005:113), and their role is considered to be "ill-defined" (Menter et al. 2010:124) - perhaps due to the limited amount of research defining them proves problematic. On the other hand, vocational teacher educators (VTEs) ${ }^{2}$ are even less visible and underrepresented in research and policy (Noel 2006). More research needs to be conducted on VTE roles as this has the potential to enhance the quality of vocational students' education. Unless there is a clear understanding of the VTE role identities, policies or quality frameworks for them cannot be set.

Having a shared understanding of the role identities of VTEs and the competencies they require would be beneficial in terms of the ways support is offered to them and how educational programs are designed. Failure to understand their roles and identities means VET-related policies will be based on flawed assumptions and partial evidence, which may then have unknown consequences for the vocational student teachers (VSTs). To date, policymakers do not emphasize the importance of TEs in general (Swennen and van der Klink 2009). In fact,

\footnotetext{
${ }^{1}$ In this paper, mainstream education refers to general/academic education as opposed to vocational education.

2 TEs working in a VET context, i.e., teaching vocational student teachers (VSTs) to become vocational teachers. Those individuals may have two identities: professional education and training identity and their other/prior professional identity.
} 
they are often referred to as hidden professionals (Livingston 2014).

This paper takes a novel perspective and puts the spotlight on the TEs working in the VET context. The Republic of Malta, an EU member state, serves as a useful case study to start building a broader understanding of TEs' role identities in the VET context.

Developing a better understanding of the role identities of VTEs in Malta is essential for shaping education and training policies, especially when the global labor market is undergoing dynamic transformation due to demographic change and changes in technology. A more supportive coherent approach could be achieved by understanding the roles of VTEs responsible for future vocational teachers.

VTEs are the crucial players for sustaining a high-quality VET teaching workforce and have a significant influence on the quality of vocational teaching and learning in schools. Neglecting them in policymaking jeopardizes the VET profession and its professional development. Moreover, not recognizing their importance may result in poor teaching behaviors. Unfortunately, the recent report by CEDEFOP about VET in Malta (2017) does not make any reference to the role of the TE.

To advance research on TEs, specifically within a VET context, the objective of this study is to understand how VTEs and MTEs in Malta describe their role identities.

To fulfill this objective, this study investigates the following research question: How do VTEs differ from MTEs in how they describe their role identities in the Maltese context?

\section{Literature Review}

VTEs influence the teacher training programs they deliver by the ways they make sense of their teacher-learning experiences (EC 2013). Therefore, role identities greatly influence how VTEs teach VSTs, which then reflects vocational teaching in general in schools or vocational colleges in Malta. This study explores whether VTEs' role identities differ from mainstream teacher educators (MTEs). ${ }^{3}$

According to Danielewicz (2001:3), a focus on professional identities is important because being a teacher requires "engagement with identity" and "teaching is a state of being, not merely ways of acting or behaving." This assumption has also been accepted by other scholars where the interpretation, judgment, behavior, and performance of individuals in their professional roles are influenced by their view on their professional identities (Stryker 1980; Beijaard, Verloop, and Vermunt 2000). Thus, investigating the role identities of VTEs can result in identifying effective ways to support them in their practice, and inspire and inform policymakers in this endeavor, leading to higher quality teaching.

In addition, TEs who work within a VET context are less visible yet still impacted heavily by the new demands on teacher training (Cort, Harkonen, and Volmari 2004). This paper argues that the professionalism of the VET workforce has been under-researched, particularly in the context of VTEs. It presents a foundation for establishing the professional role profiles of VTEs to foster understanding among policymakers and support policy learning through recommendations. However, the main

\footnotetext{
${ }^{3}$ Mainstream TEs: TEs within the higher education context.
} 
contribution of this paper is to open up a space for a more informed consideration of whether there is a significant difference between the role identities of VTEs and MTEs, through the lens of identity theory (Burke and Stets 2009).

A systematic review of the literature, which was conducted and confined only to studies within the last twenty years and to articles published in peer-reviewed academic journals in English, revealed very little on TE identities, especially within a VET context. In fact, according to Grollman (2008), many international studies do not make any reference to the teaching workforce in VET. In addition, there are many terms used to refer to the VET context, which were used to search for articles. For example, England provides vocational and work-based education within the post-compulsory education (PCE) and training, further education (FE) sector (Orr and Simmons 2010). Other terms used are the "lifelong learning sector" (LLS) (Atkins 2011) or the "learning and skills sector" (LSS) (Noel 2006). However, as stated above, research in the broader area of teaching may well be relevant.

\section{What Is a TE?}

The common definition that the EC (2013:8) adopted to describe TEs is "all those who actively facilitate the (formal) learning of student teachers and teachers." That implies that the definition is not limited to professionals in a particular educational context but also applies to all who are responsible for future teachers in their preparation and professional developmental needs (EC 2013).

It is a broad definition that does not attempt to differentiate between different educational contexts.
Particular attention needs to be placed on the VET context, which is currently being overshadowed by the general education context (Misra 2011; Springbett 2018).

\section{What Is Known about TEs in General?}

In recent years, a growing interest has been developed in studies of TEs, believed to be central to high-quality teacher education. Studies look into who they are, their challenges during induction, the support they receive, and what helps them transition from school teachers to TEs (Izadinia 2014). This focus may be seen in studies on the emerging new concept of TE identity in general education contexts, generally defined as a "socially and culturally constructed 'self' formed through a life's experiences and through communication about these experiences" (McKeon and Harrison 2010:27). Social relations and processes during the lifelong learning experience shape identity (Berger and Luckmann 1991). Swennen, Jones, and Volman (2010) point out that TEs' professional identity formation occurs when they are at work and interacting with colleagues, student teachers, and others that are all involved in teacher education. However, identity itself is not simply formed, as it takes time and is dependent on the context and work practices (Dinkelman 2011). Yet, little research has taken place on how the identities of TEs vary according to the work context. Developing a professional identity is a crucial part of the process of becoming a TE, as there is a close connection between identity and practice (Timmerman 2009). Ben-Peretz and colleagues (2010) argue that a TE's practice and their professional identity development are directly proportional to each other, meaning a TE's practice is likely to influence the professional role identity and differ ac- 
cording to the context. Thus, VTEs' role identities might differ from those of TEs working in a general education context.

Since the emergence of the notion of TE identity, researchers have investigated various factors that influence its formation (Izadinia 2014). Existing literature has explored the importance of communities of practice (Murray 2008); reflective activities (Dinkelman 2011); and various professional experiences in forming the identity of TEs (Hockings et al. 2009). However, one criticism of much of the existing literature is that researchers have argued that the profession of TEs is not well defined (Lunenberg and Hamilton 2008) and is under-researched (Swennen, Volman, and van Essen 2008).

Amongst existing literature on TEs' identity, it was found that the process of becoming a TE is influenced by three factors: personal and professional biography; institutional contexts; and a personal pedagogy of teacher education (Williams, Ritter, and Bullock 2012). Similarly, Murray (2014) argues that TEs' professionalism may be influenced by their personal life, institutional setting, and national requirements for teacher education. Likewise, a review by Livingston (2014) on TEs aimed to gain a better understanding of the concept of TE identities and their roles. Implications for teacher education and TEs were reviewed, together with the diversity of their identities and roles. However, research still needs to clarify and address who these "TEs" are and how they are supported. This is particularly important for those TEs working in a VET context because of the diversity within it. In fact, Cochran-Smith (2003) argues that one has to define the identity of TEs first before taking into consideration their professional development. The following section sheds light on studies that focus on teacher education within the VET context.

\section{What Is Known about TEs in a Vocational Education and Training Context?}

The little knowledge about TEs in general is mainly focused on school TEs (Noel 2006) and current literature on TEs within a VET context is sparse (Springbett 2018). In particular, the latter are rarely studied, and their lives have been described as "secret" (Noel 2006). Noel (2006), Crawley (2013), and Springbett (2018) inform this paper as they are the three publications that have specifically focused on TEs working in a VET context.

Large-scale investigations of the professional situation of TEs in the lifelong learning sector (LLS) were conducted by both Noel (2006) and Crawley (2013). Although Noel's (2006) study provided the most comprehensive demographic profile of the TE profession in the PCE sector to date, she does not explore the meaning of a TE identity within the LLS. The aim of Crawley's (2013) research was to enhance the professional well-being of TEs within the PCE sector by shedding light on various ways of supporting them. Although Crawley (2013) highlights the essential characteristics that TEs should have, his attempt to provide a clearer and broader picture of their professional situation in the PCE sector and issues of their professional identity or attempts to define it was neglected.

These two studies (Noel 2006; Crawley 2013) contribute information about TEs, in general, by considering age, ethnicity, and gender. However, there seems to be no in-depth understanding of what their professional identity consists of. Fur- 
ther research carried out by Springbett (2018), who explored the professional identities of TEs in three FE colleges, contributes some depth to the subject. Springbett (2018) draws on a small-scale case study where she explores how the FE sector positions TE identity. Her findings demonstrate how various factors impact the TEs within this vocational context. She claims that avoiding obscure links between professional concerns and policy landscapes is best done by understanding TEs as a heterogeneous occupational group.

Although these three previous studies provided an overview of the TEs' demographic profile, together with how the FE sector positions TE identity, no attempt was made to define the meaning of a VTE professional role identity within this educational sector, or how TEs perceive their most prominent and salient role identities.

\section{Theoretical Perspective}

Burke and Stets' (2009) identity theory was chosen as the main theoretical lens to understand the role identities of both MTEs and VTEs. Choosing identity theory from the structural symbolic interactionism (SI) perspective as an analytical lens enables the researcher to focus on meaning - "what it means to be who one is" (Stryker 1980). Specifically, the identity model within this theory was used together with the concepts "identity prominence" and "identity salience" to investigate how the participants view and rank their meanings of identity (Burke and Stets 2009). This theoretical perspective shows that individuals develop a shared meaning of identity through symbolic interactions. Choosing SI as the main theoretical lens throughout the study offers a deep understanding of TEs' identity at a more granular level rather than merely seeking to consider the institutional or national level. That enables the researcher to explore the dynamic nature of TEs in the narration of their identity and how they posit themselves.

The following section explains the theoretical model that underpins this research. Ultimately, to understand a role identity well, it needs to be seen as a process.

\section{Identity Model}

Identity theory stems from two sets of ideas: SI and perceptual control theory (Powers 1973). Four main components make up the identity model each time an identity is activated: input, the identity standard, comparator, and output. Each component is a process linked together in a cyclic arrangement of processes about meanings within the environment and the self, as shown in Figure 1.

Figure 1. Basic Identity Model

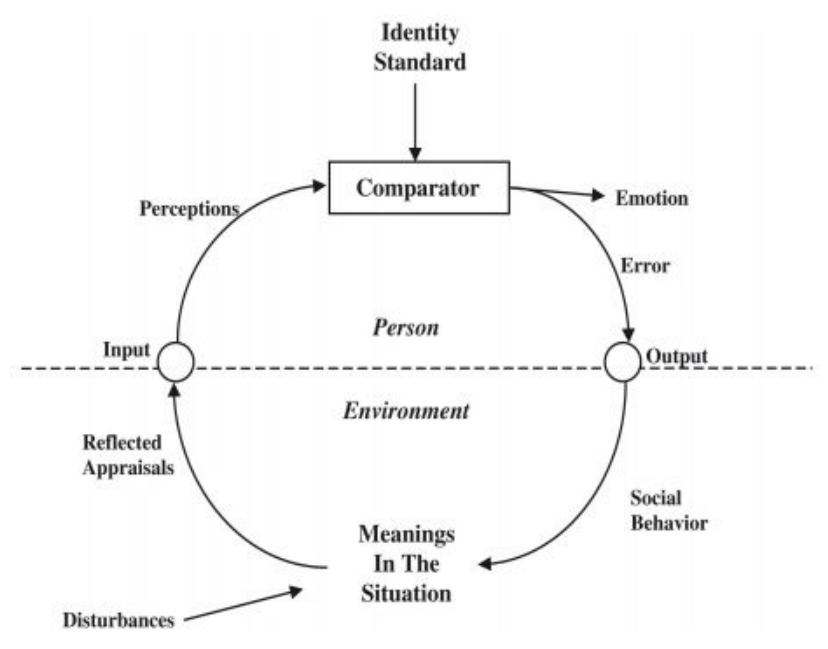

Source: Burke and Stets 2009:62. 
The individual's reflected observation of their self in the situation are the inputs to the system. Perceptions are meanings relevant to an identity in a particular situation. The identity standard is a set of several meanings that make up an identity and may be viewed as defining the character. The comparator compares the inputs to the identity standard. An "error signal" (Burke and Stets 2009:29) is produced when there is a difference between the input and the identity standard and this might cause stress and negative emotions. The person's behavior, which is based on the error signal from the previous process, is the output of the model. If an error signal was experienced in the previous process, this might cause the person to modify their behavior to reduce the discrepancy, which is the ultimate aim of this model. The cyclic process keeps on going until the perceptions match the identity standard within the comparator and the identity is verified, which leads to positive emotions. People become distressed when they are not able to verify their identity (Burke and Stets 2009).

Role identity guides the perceptions, expectations, and behaviors of people by providing structure and meaning to their lives and situations (Burke and Stets 2009). Thus, when there are certain goals or aims relating to a role, an expectation is set. However, the way to achieve a goal is not specified (Burke and Stets 2009), and, therefore, the level of achievement could affect the perspectives of individuals in terms of their role identity.

\section{Research Design}

\section{The Maltese Case-Study under Consideration}

The main participants of this study were TEs in the Master in Teaching and Learning (MTL) program
(MQF level 7) at the Faculty of Education (FoE), University of Malta (UoM). This program has been in operation since October 2016. It replaced two former pre-service teacher education programs and is an entry-level qualification for teachers in early childhood education, primary education, and secondary education. It is a two-year full-time course where students should have an undergraduate degree in the subjects they will teach. From October 2017, the FoE started offering the MTL in VET, specializing in various vocational subjects as part of the government's "My Journey: Achieving through Different Paths" education reform (UOM 2017). This reform will be implemented in lower secondary schools in the school year 2019-2020to move from a 'one size fits all' system to more inclusive and equity-oriented programs catering to pupils' aptitudes (Ministry for Education and Employment-Malta 2016).

This reform aimed to promote inclusion and respond to diversity by allowing students to choose from several education routes, which include general, vocational, or applied subjects for their elective subjects beyond the core curriculum. The intention of this reform, apart from promoting inclusion, was to diminish the number of early school leavers by making education relevant to various students in response to a changing labor market. VSTs graduating from this MTL in the VET program are then eligible to teach VET subjects in secondary schools. Currently, VSTs have their teaching practice at MCAST, where they teach students who are following foundation certificate programs that lead to MQF levels 1 to 3 (secondary education level). This reform included TEs specialized in VET, who are the participants within this study. Even though the main focus of this study is on the professional role identity of the VTE, MTEs are interviewed to see whether there are any differences between these groups. 


\section{Philosophical Underpinnings}

The philosophical stance taken in this research comprises a subjectivist ontology and a constructivist epistemology. A qualitative methodology located within an interpretivist paradigm was chosen as this approach concentrates on interpreting and understanding "human actions and cultural products" (Benton and Craib 2001:182). Moreover, SI is an approach within the scope of interpretivism (Bloomer and James 2003:252).

\section{Methodological Approach and Research Methods}

The semi-structured interview technique was chosen as it was felt to be the most appropriate one to allow participants the freedom to add more information when required (Drever 1995). Considering that the perceptions of TEs needed to be investigated, semi-structured interviews helped in gaining a deeper understanding. Moreover, they were felt to be more appropriate considering the small-case study within Malta.

Convenience and purposive sampling were adopted for selecting a small number of participants. The main criterion for the purposive sampling in this study was ideally to include all the VTEs teaching on the MTL in VET program. Convenience sampling was undertaken for the other participants (MTEs) who were willing to take part.

Data were collected during the academic year 2018/2019. The MTL program within a VET context was offered in only two disciplines: Health and Social Care (HSC) and Media Literacy. The dean of the FoE circulated the researcher's request via e-mail to all faculty members within the MTL program to participate in the study. Six VTEs and seven MTEs from various subject disciplines agreed to take part in the study and contacted the researcher via e-mail to proceed with the inter- views. All participants requested to be interviewed in their natural working habitat, that is, their offices. All educational research guidelines and ethical rules have been followed and approved by the University's research committee.

\section{Participants}

Tables 1 and 2 give a brief overview of the participants.

Table 1. VTEs.

\begin{tabular}{|c|c|c|c|}
\hline $\begin{array}{l}\text { VTE } \\
\text { No. }\end{array}$ & $\begin{array}{c}\text { Subject } \\
\text { Discipline }\end{array}$ & $\begin{array}{l}\text { Full-Timer } \\
\text { (FT) / Part- } \\
\text { Timer (PT) }\end{array}$ & $\begin{array}{l}\text { Experience in } \\
\text { industry }\end{array}$ \\
\hline 1 & $\begin{array}{l}\text { VET General } \\
\text { Pedagogy }\end{array}$ & FT & N/A \\
\hline 2 & Media studies & PT & $\begin{array}{l}\text { Yes, as a media } \\
\text { producer }\end{array}$ \\
\hline 3 & Psychology & PT & N/A \\
\hline 4 & HSC & PT & Yes, in HSC \\
\hline 5 & HSC & PT & $\begin{array}{c}\text { Yes, as a social } \\
\text { worker }\end{array}$ \\
\hline 6 & HSC & PT & Yes, as a scientist \\
\hline
\end{tabular}

Source: Self-elaboration.

Table 2. MTEs.

\begin{tabular}{|c|c|c|}
\hline $\begin{array}{c}\text { MTE } \\
\text { No. }\end{array}$ & Subject Discipline & $\begin{array}{c}\text { Full-Timer (FT) / } \\
\text { Part-Timer (PT) }\end{array}$ \\
\hline 1 & Physics & FT \\
\hline 2 & Chemistry & FT \\
\hline 3 & Art & FT \\
\hline 4 & Italian & FT \\
\hline 5 & Philosophy of Education & FT \\
\hline 6 & Business Education & FT \\
\hline 7 & Sociology of Education & FT \\
\hline
\end{tabular}

Source: Self-elaboration. 


\section{Data Analysis}

Semi-structured interviews were approximately an hour in length and audio-recorded. These interviews were all transcribed verbatim. Data analysis started in conjunction with the data collection as it is one of the essential attributes of qualitative research compared with quantitative research (Merriam 1998).

Thematic analysis (TA) was the method used to identify themes and patterns of meaning across the transcripts of the semi-structured interviews (Braun and Clarke 2013). Specifically, a mix of inductive and theoretical TA was used. Inductive TA "aims to generate an analysis from the bottom (the data) up; analysis is not shaped by existing theory (but analysis is always shaped to some extent by the researcher's standpoint, disciplinary knowledge, and epistemology)" (Braun and Clarke 2013:175). This type of inductive TA was mainly used for the participants' responses. On the other hand, theoretical TA was also used, as the interview questions were constructed on Burke and Stets' (2009) identity model, so the analysis was also guided by its theoretical concepts (Burke and Stets 2009). According to Braun and Clarke (2006:87), TA reveals "experiences, meanings and the reality of participants." Their guide to conducting TA was followed (Braun and Clarke 2013:202).

\section{Findings}

The section outlines findings that emerged from the semi-structured interviews conducted with both MTEs and VTEs. The overarching themes: aims and principles; ideal TE (identity standard); and role identity are presented below. Each theme has a clear focus, scope, and purpose, based on Burke and
Stets' (2009) identity theory as discussed previously. Together, they provide a rich, coherent, and meaningful picture of what it means to be a TE in Malta. Specifically, this section explores how TEs construct their role identities and how emotions shape these identities, and the consequent outcomes for their practice.

\section{Aims and Principles of TEs}

An overarching theme is the "aims and principles" or perceptions that TEs in Malta have about their role identities. VTEs viewed them in terms of: time; reflecting on their practice; and having the adequate knowledge, skills, and competencies (KSCs) to produce vocational teachers of high quality. For example, VTEs portrayed time through current affairs and context. The influence of time and context is captured in the following comment from VTE 1:

VSTs should be given a context where they can apply the theory and skill into practice. You need time management, be creative, be aware of industrial skills. You have to keep abreast with today's society.

VTE 1's comments provide examples of how important it is that VTEs and student teachers remain aware of current affairs, in terms of technological changes and advancements. Thus, both VTEs and VSTs' role identities involve interaction with wider society, particularly industry and hands-on approach to apply theoretical concepts in practice. VTE 2 also refers to the notion of time and claims that it is the responsibility of VTEs to remain up to date with what is happening within the industry. VTE 2 states:

How can we understand the criticism that the media highlights, if we do not know our own context inside 
out? Therefore, apart from our own local context, it is within our responsibility to also tell them [student teachers] what is happening within the EU context. How can we know the reason why Malta took a certain direction, if we don't know what's happening in the EU? A vocational teacher at the end of the day needs to know what's happening within the industry at a local and also at a broader context to remain up to date.

This extract demonstrates that it is crucial for educators within a VET context to keep abreast with what is happening around them and in the wider context and communicate this to their student teachers. In addition, the spillover of the commitment to VTE 2's former professional role identity in the industry can put tremendous pressure on the current role identity of a VTE to complete its expectations and responsibilities. VTE 2 feels that if the industrial context is omitted from the teaching, the role expectations of a VTE will not be fulfilled, which might trigger a discrepancy in the future when vocational student teachers become fully qualified to teach. In fact, this study is based on the premise that the role identities of VTEs are similar to those of vocational teachers due to the nature of the subject discipline. Thus, VTEs are aware of their responsibility to pass these attributes to their student teachers. The meaning of their role identity is created through interaction with other parties beyond the VET context. This is linked to the next two sub-themes about self-reflection and KSCs.

Self-reflection offers educators an opportunity to think about what works and what does not work in their professional practice. VTEs said that this made them think deeper and reflect on their practices and about why certain decisions were taken. They described how it results in effective teaching as they improved their practice thereafter. For example,
VTE 3 emphasized the importance of self-reflection and states:

Another responsibility that we, TEs, have is to tell our student teachers that we must constantly evaluate and reflect on the vocational education system and the lessons.

This extract links with the previous sub-theme of keeping up to date with what is happening in the industry and reflecting and evaluating the current practices. This demonstrates the intensive commitment to meeting the aims and principles of a VTE. VTEs need not only to reflect on their teaching practices but also know what is happening in the labor market, which is linked to the next sub-theme.

As discussed previously, it is within the VTEs' interests to remain abreast with what is happening in the labor market. That leads the VTE to explore different approaches to the KSCs that are required within it. Learning for employability is considered essential by the VTEs. The word "industry," which refers to the labor market, was constantly being mentioned by them. For example, VTE 4's aim was to make sure that student teachers were well prepared within the vocational stream and in the pedagogical aspect, which would lead to high-quality vocational teaching. In fact, VTE 4 said:

[My] aim is to produce vocational teachers of high quality.

VTE 1 concurred with this aspect:

Vocational education is different. Apart from providing them the skills, you also have to pass on the competencies. That is, there is the theory, there is the skill, then you should be capable of applying that theory and that skill to unfamiliar situations. 
Here, both VTE 4 and VTE 1 demonstrate the importance of being competent in the skill and not only being knowledgeable. In fact, VTE 4 emphasizes that it is within their responsibility to prepare students both in the vocational and pedagogical aspects, that is, teach them how to transfer that knowledge to others. Similarly, VTE 1 explains the importance of linking theory to practice, even in unfamiliar contexts.

These extracts indicate that occupation-specific skills are not enough for VET students to adapt to new life situations and engage in further learning; key competencies are also required. VTEs described why these are essential for employment. Moreover, these extracts also depict how the professional role identities of VTEs are not static as they gain experience and constantly need to adapt to the changing requirements of the labor market.

On the other hand, MTEs viewed the "aims and principles" as: helping student teachers become good teachers; helping future teachers become reflective practitioners; and "loving" the subject discipline and then teaching its pedagogies. For example, MTE 1 and MTE 2 describe how helping student teachers is their main focus. MTE 1 says:

I would like my student teachers to think of the learners first. That is my main thing. What does it mean to learn? What type of teaching should I do for that learner? I, as a lecturer, would have failed. I don't want them to have the knowledge just to pass their exams.

Here, MTE 1 sees teaching as student-focused, both in the TE's work and that of future teachers; and teaching and learning should not be about passing exams but based on reflective practice and adapted to their learners.
Like MTE 1, MTE 2 described how student teachers should always put the needs of their learners first and says:

Teachers should think about their students and not just about the content. They need to connect the needs of the subject to the needs of the students. You cannot emphasize the learning outcomes and forget about the realities you have in front of you. If that happens, learners start losing their focus. So, the challenge for the teacher is to be flexible and adapt to the situation.

MTE 2, like MTE 1, is student-focused. Flexibility is key to adapting teaching content to the needs and abilities of students.

Similarly, MTEs describe ways how they help future teachers become reflective practitioners. This subtheme explores how MTEs evoke their aims and principles with their student teachers. For example, MTE 3 says:

My aim as a TE is to help my student teachers become reflective practitioners. My desire is not to have teachers who go to class and teach their subjects, and that's it. I want them to be reflective practitioners in the sense that whatever they do in class, they need to reflect upon, prior to going in class and after going out of class.

This extract demonstrates MTE 3's ambitious aim that one has as a TE. MTE 3 suggests that to be a good teacher, reflection before and after teaching is necessary. MTE 3 aims to engage the student teachers in reflective practice.

MTEs highlight the importance of knowing the subject profoundly before teaching its pedagogies. This sub-theme captures the underlying aims of MTEs 
regarding content knowledge. According to them, a teacher is not able to teach a subject if they understand it at a superficial level. In addition, a teacher cannot communicate any enthusiasm, and teaching would be pointless. For example, MTE 4 says:

The subject has to be ingrained within you. It has to be in your blood; you have to know it really well.

MTEs highlight the importance of knowing the subject profoundly before teaching its pedagogies. In addition, both MTEs and VTEs shared a common aim and principle, that of supporting student teachers. Regardless of which role identity is, the fact that they appear to be so interconnected on this aim and principle shows how strong the commitment and thus salience of the role identity of being a TE. It is, therefore, logical to suggest that this study is based on the premise that the role identities of VTEs are also similar to those of MTEs, bearing in mind the nature of teacher training programs.

\section{Ideal TE (Identity Standard)}

According to Burke and Stets' (2009) identity model, each identity contains a set of meanings that defines the character of that particular identity and makes up the identity standard. This theme, "ideal TE," portrays the set of meanings that TEs have, which characterizes an ideal of their role and serves as a point of reference in the identity process within the identity model.

VTEs viewed the ideal TE in three different ways, all of which were directly related to the VET context. According to them, the ideal VTE should be pragmatic and dynamic; must have industrial and teaching experience; and should maintain practical links with the labor market to keep informed. For example,
The person needs to be very pragmatic and very dynamic; someone who's capable to bridge theory to practice and relate it in a very relevant mode. It cannot be something that remains theory on paper. [VTE 1]

The emphasis of vocational education is hands-on. [VTE 4]

Here, VTEs emphasize that VTEs' teaching approach should be practical not only theoretical; and bridge the gap between the two. In addition, the need for teaching to be exploratory in nature and have a "hands-on" approach is crucial. Vocational teaching needs to be pragmatic, dynamic, and practical to develop and maintain the highest standards in students' technical competencies, pedagogical skills, and transversal competencies. The latter are those skills and attitudes, such as organizational skills, that are relevant to a broad range of occupations.

Considering that technological changes impact future job trends, they suggest that VTEs should be flexible in their practice and explore new ways that accommodate these changes. The implication is that their professional role identities are constantly changing, which is linked to the next sub-theme where according to VTEs, TEs working in a VET context should have industrial experience. The connection with industry was also highlighted in the aims and principles of VTEs. For example, VTE 6 says:

They definitely need to have industrial experience and then teaching experience. So, you need to have both kinds of experience.

Considering that the aim of VET is learning for employability, the ideal VTE should have industrial experience within the subject field and also experience within pedagogy. They argue that high-quality 
teaching in VET is guaranteed by having teachers who have prior occupational experiences. That leads to the next sub-theme where VTEs describe the importance of links to the labor market. For example, VTE 6 states that:

TEs should make sure to remain up-to-date, to know what is being done out there.

One way of achieving this would be through industrial visits to help VTEs to remain abreast with the latest knowledge and allow them to discuss future skills trends in the labor market. This depicts how the role identities of VTEs are internalized by social role expectations. VTE 6's emphasis on remaining up-to-date may indicate uncertainty of their role identity if they do not keep abreast with the labor market. VTEs' role identities are not solely set by them as a professional group, but also by the expectations of the labor market. As a result, there may be tensions and dissonances in verifying their professional role identities as their identity standard.

Thus, the interviews show that identity is not only about how VTEs perceive themselves, but how the labor market and society perceive them. Moreover, it suggests that within a SI perspective, the focus in the case of VTEs is on how identities are developed and ascribed in interactions with the labor market.

For MTEs, the ideal MTE should be enthusiastic about the subject discipline and keep abreast with the latest research. These were also highlighted in the aims and principles of a TE. In addition, both VTEs and MTEs have stressed the importance of keeping good TE-student teacher relationships. That is likely to help in the learning process of student teachers. They also emphasize the importance of the personal quality of caring over the academic ability of teachers or TEs. This quality relates to "person identities" in Burke and Stets' (2009) identity theory and they may guide the role identities.

\section{Role Identity}

This theme explores the role identity of the TEs in this study in terms of three sub-themes: roles; prominence; and salience hierarchy of identities. It considers how TEs construct meanings for their different roles. According to identity theory, a role is "the set of expectations tied to a social position that guide people's attitudes and behavior" (Burke and Stets 2009:114) and provides structure, organization, and meaning for TEs.

\section{Roles}

This sub-theme captures more than one characteristic that TEs used to describe what their role meant to them. Burke and Stets (2009:115) claim that role identities have different meanings for different people. Each role is described in depth below. It also explores how TEs cope with multiple roles and which they consider conflicting. Both VTEs and MTEs mentioned curriculum development, teaching/lecturing, and examining student teachers as their multiple roles. VTEs distinguish themselves in their teaching approach, considering that their subjects are vocational. They emphasize that starting from the practical aspect and moving to the theory was their adopted approach when compared to the traditional way of teaching that is more content-driven and students are passive learners. Specifically, VTEs consider that the most effective learning in VET is by giving importance to learning through the application of knowledge in realist contexts. VTEs feel responsible to ensure 
that learning is connected to the workplace and that students would be learning for employability. This type of learning approach is also in line with the findings of Said (2018) where authentic learning was the preferred learning environment for higher vocational students following a vocational bachelor's degree program. The difference between this current study and Said's (2018) study is that the participants were not student teachers in VET but were higher vocational students following a vocational bachelor's degree program. However, the comments of the VTEs of this study suggest they know exactly what type of learning approach vocational students prefer, and that is why authentic learning is emphasized to student teachers.

VTEs also mentioned supporting student teachers and MTEs mentioned administration, researching, and dissertation supervision as part of their roles.

The above findings concur with other researchers, suggesting that people can activate multiple meanings to their role identities (Burke and Stets 2009). Both VTEs and MTEs have attributed multiple meanings to their professional role identity. Thus, the next sub-theme discusses how these TEs cope with the multiple roles.

\section{Coping with Multiple Roles}

Support from colleagues, relevant experiences, self-reflection, and personal characteristics were the main coping mechanisms between various roles. VTEs specifically described how their former occupational identity guided them in their role as a VTE. VTEs suggested that their former occupational identity was not replaced by their new role identity as a TE, but it has helped them to transition. With regards to the latter, person identities are also recog- nized by identity theorists (Burke and Stets 2009). They are based on the qualities and characteristics that define the person as a unique individual rather than as a role-holder. Thus, the person identity is seen to be operating across various roles and situations, and at times is likely to be activated more than the role identity. In certain situations, individuals rely on their person identity, which serves as the identity standard, and which eventually guides the identity-verification process (Burke and Stets 2009). For example, VTE 2 specifically states:

It was not difficult to cope with multiple roles. My motto is that the things you wish for yourself, do them to others. Therefore, I always give my best. Being honest and transparent is my way.

This suggests that the character of the individual plays an important part in every role identity that is taken. Moreover, person identity is like a master identity since the meanings within it influence the meanings within one's role identity (Burke and Stets 2009).

The next sub-theme discusses how the roles TEs mentioned might conflict with one another.

\section{Conflicting Roles}

Multiple role identities could be related to one another and are set to different levels. That could result in identity conflicts where there is a role conflict. A discrepancy between these role identities can occur when they are activated at the same time. Identity theory suggests that levels of distress are felt because of these discrepancies (Burke and Stets 2009). TEs experienced conflicting roles and mentioned the examining role, as opposed to the teaching/mentoring role. For example, VTE 3 says: 
Honestly, in the beginning, I was afraid that my roles do conflict with one another as I was first teaching them, and then the time arrived when I had to assess them during their exams and teaching practice visits. However, the fact that all student teachers were respectful helped me overcome this fear.

It is suggested that when a TE manages conflicting roles successfully, such as the ones above, they can build a good relationship with student teachers; it not only helps student teachers in effective learning but also impacts positively on the identity formation of the TE.

Moreover, MTEs describe how the mentoring role conflicts with the examining role. For example, MTE 4 says:

There's a very fine line when being a mentor and an examiner at the same time. I'm referring to the teaching practice here. But, the fact that I keep constant communication with my student teachers, very often, they already know what my judgment will be. I discuss everything with them. After each visit, I discuss the report I give them and invite student teachers to my office to discuss it thoroughly.

This extract also suggests the benefits of building a good TE-student teacher relationship and how the role identity of a TE is verified through open communication with both parties (Burke and Stets 2009).

\section{Prominence Hierarchy of Identities}

This sub-theme within "role identity" captures how important identity is for TEs. Since TEs have multiple role identities, as was explained above, this sub-theme explores which role or roles are more prominent in the way VTEs and MTEs think about themselves. The higher the identity in the prominence hierarchy, the more important it is. However, where an identity appears in the prominence hierarchy depends on three factors (Burke and Stets 2009). One of the factors is how much individuals obtain support for the identity they are claiming. The more support they have, the higher that identity will be in the prominence hierarchy. Another factor that affects it is how committed individuals are to their role identity. The placement of identity in the prominence hierarchy is also influenced by the rewards individuals get from that identity, both extrinsic and intrinsic (Burke and Stets 2009). Intrinsic rewards are the gratifications that individuals experience internally for that particular role they perform, whilst extrinsic rewards are things such as money, prestige, and favors. Therefore, this sub-theme is divided into three categories: support; commitment; and rewards, and each category explores which roles are prominent for TEs.

\section{Support}

VTEs described four main roles that were most supported. These were: (1) administrative, (2) curriculum development, (3) examining role during teaching practice, and (4) writing exam papers. The support was either from their colleagues or from the department they worked in. The one and only role that was given the least support for VTEs was the teaching role. All VTEs said that they could not receive support on lecture preparation when compared to other roles. TEs felt reassured when they received the necessary support. The more support they received from the department or from their colleagues, the higher that role identity is likely to be in the prominence hierarchy. However, support is not the only factor that impacts prominence hierarchy. Another factor that affects this is commitment. 


\section{Commitment}

This sub-theme explores which roles TEs are most and least committed to. VTEs and MTEs have suggested that the role they were most committed to was the teaching/lecturing role. Moreover, VTEs were also committed to the examining role during the teaching practice. Administration was the role that many MTEs found they were least committed to.

The administrative role does not appear to add any value to the role identity of a TE, but it is still recognized as needing to be done.

The final factor that affects this are rewards.

\section{Rewards}

The extrinsic rewards that both VTEs and MTEs received were from the student teachers. For example, VTE 1 says:

I feel very happy when students appreciate what you do with them.

It is suggested that appreciation motivates TEs in the role identity. Similarly, other MTEs also feel rewarded when student teachers thank them for the work they do. For example, MTE 4 says:

Sometimes I get ex-students who come up to me and tell me "thank you" or give me a gift as a form of appreciation. These give me the courage to go on.

MTE 4 admits that when student teachers appreciate the work, it motivates them and gives them an incentive to carry on. Moreover, such appreciation also acts as a verification for their role identity as a TE and confirmation that one is on the right track.
In addition, MTEs receive extrinsic rewards in the form of positive emotions when other researchers acknowledge their work.

The intrinsic rewards were the positive feelings VTEs and MTEs felt when they overcame certain challenges, when a lecture turns out well and when student teachers follow their advice during teaching practice. This suggests that commitment and perseverance help in identity verification. Both intrinsic and extrinsic rewards motivated TEs to keep on striving, which helped them in their professional role identity formation.

\section{Salience Hierarchy of Identities}

This sub-theme within the broad theme of "role identity" captures which role or roles TEs had to activate in a situation because of norms or pressures from others. According to identity theory, identity salience reflects the situational self rather than the ideal self. It is the likelihood of identity being invoked across situations.

Both VTEs and MTEs emphasized that their teaching and mentoring roles were the most important, which need to be activated across situations. Participants feel that they aim to teach student teachers well and to support them in their needs.

The least important role for both VTEs and MTEs was the assessing role. For example, TEs mentioned that their focus is on the learning process rather than the grade they give during the teaching practice. In addition, one participant also mentioned the counseling role as the least important as it was not a priority and is seen beyond the remit as a VTE. However, as a professional, this participant responded to the expectations of the situation rather than to their desires (Burke and Stets 2009). 
In summary, the VTEs' perceptions of their professional role identity prioritized not just knowledge but also skills and competencies, distinct from the pedagogic practice. The identity standard that represents the professionalism of these VTEs may be influenced by their biographies, including their former occupation identity and training, together with their educational and personal experiences, and person identity. Moreover, how VTEs viewed their understanding of their professional role identity will frame notions of effective vocational teaching and ideas of what makes student teachers become "good" teachers in the VET context.

The last two sub-themes show that the more prominent a role identity is for the VTEs, the more likely it will be invoked in a situation. Moreover, the more support and rewards VTEs receive for a particular role, the more that role is activated across other role identities. In these findings, VTEs remark that they are mostly committed to their teaching and examining roles, amongst other roles. VTEs experience positive emotions from having good relationships with their student teachers and being responsible for bridging theory with practice and learning for employability. These may be associated with their identity standard.

On the other hand, the perceptions of MTEs on the role identity prioritized knowledge of the subject matter and the research that underpins their teaching. In addition, they attributed multiple meanings to their roles and not all of them managed to cope with their different role identities. The two role identities that were seen to be conflicting were the lecturing and examining roles; MTEs are mostly committed to the lecturing role. In addition, they find the administrative role least important as it is time-consuming.

\section{Discussion}

The experiences of a small group of TEs within the MTL program were examined. It was observed that the educational contexts in which they teach differ not only in the subject disciplines but in terms of their cultures. Findings show that both VTEs and MTEs played roles in interaction with their student teachers and their colleagues. The internalized meanings of the roles that participants apply to themselves help to construct their professional role identity as TEs. These varied slightly between and among both groups of participants. That is because the meanings are derived from the individuals' distinctive interpretations of the role. VTEs put most emphasis on KSCs, bridging the gap between the theoretical and the practical components, and on industry outreach. On the other hand, the MTEs emphasized content knowledge and research, considered as a key characteristic for university TEs in Europe to develop a researcher identity (Swennen, Jones, and Volman 2010).

There was also a difference between full-timers and part-timers in the roles they described within the same group of participants. Full-timers described an additional administrative role when compared with the other roles that were described. Respondents drew on similar discourses when discussing that their priority is to care for student teachers.

Moreover, it was observed that the institutional context and previous experience left an impact on their identity standard. MTEs portrayed how the community of practice influences their professional role identity. However, since all but one VTE were part-timers who spend less time on campus when compared with full-timers, their identities are not necessarily influenced by the UoM as an academic 
institution. VTEs are more influenced by the labor market and their full-time occupation, which have an impact on their identity standard. In addition, the employment status of VTEs as part-timers did not have any influence on the underpinning of their teaching. Although VTEs saw research as important, they felt that it was not a necessity for them due to the nature of VET.

As the findings depict, the professional role identity of TEs contains a large set of meanings, showing that more than one characteristic was used to describe what their role means to them. However, the participants within the VTEs' group appear to think alike and act alike, showing that there is uniformity of thoughts and actions, indicating their social group identity (Burke and Stets 2009). As their perceptions and behavior were similar, this shows that VTEs took on a clear group-based identity. Findings show that they acted in concert; they identified with and evaluated themselves positively in the group, all giving importance to the needs of industry and adopting a hands-on teaching approach.

It can be observed that the role identities are integrated with the group identities, which makes it difficult to disentangle them from each other as identity theory suggests (Burke and Stets 2009). Findings show that VTEs, although having discussed and enacted their roles individually, share very similar ideas on what it means to be a VTE. Moreover, this study echoes previous attempts to theorize ideas that vocational teachers should be conceptualized as "dual professionals" (Orr and Simmons 2010), bearing in mind that they hold the identity of a teacher, or in this case, a TE, as well as that of their former or other occupation (which is their vocational expertise). This shows that VTEs are more distinct when compared with the differ- ent role identities of MTEs, which are more related to content knowledge.

Concerning TEs verifying their identity, some participants felt unable to perform well in their role and experienced negative emotions, just as is predicted in the identity model (Burke and Stets 2009). For example, TEs from both groups felt negative emotions when student teachers do not follow their advice. TEs felt that they needed to act on this and discuss issues with their student teachers. Both groups experienced positive emotions when they felt that their work was being appreciated by their student teachers. That led TEs to continue behaving in the same way as their identity was being verified.

Both groups have ranked the meanings they attributed to their role identities differently. Some participants gave their primary importance to teaching, showing that identity prominence was on that component. Then, others were mostly committed to the role of examiner during the teaching practice. They also described moments when identity salience had to be invoked in certain situations. For example, even though their least important role was that of a counselor, there were moments when they had to activate and prioritize this role over their prominence identity to help student teachers in particular situations. These situations affirm the claim that whilst identity salience and identity prominence are correlated with each other, they are still different in the underlying concept (Stryker and Serpe 1994).

\section{Conclusion}

The study particularly focused on the professional role identities of VTEs and compared them with MTEs' on the island micro-state of Malta where re- 
spondents were Maltese and all delivered courses within the MTL program at one institution.

This study contributes to the understanding of TE identity standards by demonstrating through analysis of interview data the multiple-meanings TEs assign to their roles, how they cope with multiple roles, conflicting roles, identity prominence, and salience.

The introduction of this paper discussed the reasons why it is important to understand the professional role identities of this target group. Primarily, VTEs are underrepresented in research and policy and misapprehended as an occupational group, and not recognizing their importance may result in poor teaching behaviors. In addition, failing to understand their role identities, policies in the VET sector might be based on flawed assumptions, which may then have unknown consequences for the VTEs, the VSTs, vocational teaching in general, and the labor market. VTEs are the backbone of initial vocational teacher education, as key individuals who deliver teacher training programs and influence future vocational teachers. Hence, they are in a position to regulate the vocational teaching profession, the professional conduct of vocational teachers, and establish professional standards in VET.

This research has shown that there are differences between VTEs and MTEs about what underpins or should underpin their teaching. For VTEs, it is industrial experience and industries' needs, whereas for MTEs, it is knowledge based on research and teaching experience. These differences are influenced by the perceptions they have about their professional role identity, even though it was happening within the same institution. The findings in this study show not only what their professional roles are but also why VTEs perform such roles, some of which were a matter of choice. Roles were also affected by employment status, as full-time staff had additional administrative roles.

This study is unique by presenting the results of a qualitative study on VTEs' perceptions of their professional role identities. This professional group has been neglected in the research literature and policy. Through the exposition and conclusions derived, it demonstrates what actions and policies are suited to the characteristics of an island micro-state.

Through the qualitative findings of this study, it is concluded that the professional role identity of VTEs is diverse and dependent on multiple sources of identification: their former occupation/profession; the labor market; and VET. Thus, VTEs are better understood as having a multi-dimensional identity, and should not be imposed with established policies borrowed from other educational contexts.

\section{Strengths and Limitations}

A thematic approach was used to analyze all interviews. A clear and consistent definition of identity was used throughout this paper to guide the analysis. Stryker's (1980) definition from the SI perspective to define identity as "what it means to be who one is" was used in this study. Moreover, analyzing the professional role identities of VTEs from a SI perspective offered the ability to go in-depth and examine them at a granular level.

A limitation that is important to highlight is that this study focused on the role identities of TEs. Although social identity theory (Burke and Stets 2009), that is, the group identity, was referred to in the discussion, and professional background details were 
given for all participants, the primary aim of this research related to role identity, as it depicts the professional identity and not the social or person identities. Moreover, it was not in the scope of this study to analyze the data according to age, gender, race, or other forms of social status.

\section{Contribution to Theory and Policy}

Most researchers have examined the identity process using the survey approach (Carter 2013). It is very difficult for the researchers to capture the context within which the identity emerges using a survey approach. Thus, using a survey approach results in learning about identities in isolation from their surroundings (Burke and Stets 2009). This empirical study moves identity theory in a new direction by examining the role identity process of TEs, using a qualitative methodological approach and capturing the context within which their role identities emerge, based on a case study.

Findings from this study indicate that policies need to be established to support the professional role identity of VTEs and their professional development. This study paves the way for contributing to a shared understanding of what it means to be a VTE.

\section{Further Research and Recommendations for Policymakers}

Future work could examine the interaction and the relationship of role identities to social and person identities from the structural SI perspective and how such an interaction could impact the behavior of VTEs. Examining how multiple identities interact with each other extends the study of the professional identities of VTEs.
Considering that VTEs are better understood as holders of multi-dimensional identity and that they are under pressure from employers to diversify and expand their roles, policymakers should pay attention to limiting VTEs professional role identities. One suggestion is to have VTEs that are specialized in the teaching of general vocational pedagogy, and others who can specialize in collaborating with industry partners. That will guarantee that the ethical and epistemic status of the vocational teaching profession has a far wider significance than it currently has, and future vocational students are better prepared for the workplace. This will have a positive impact on society and the economy. This would guarantee that all professional roles are performed irrespective of which VTE performs them. Additionally, having VTEs specializing in one area will make it easier for them to develop their skills in more depth and keep abreast with the new developments in the areas they specialize in (whether it is new teaching methods, new technologies, or business practices). That also helps them to take control of their professional needs and manage their professional support as it is essential that VTEs become active agents in their development and be more able to verify their role identity and its prominence in their hierarchy of role identities. With this recommendation, it would be possible to keep up with the challenges of the fourth industrial revolution. The aim of all this is to have an effective vocational teacher training program that will produce exceptional vocational teachers who are well-equipped to help vocational students make the move from school to work.

To conclude, this study has given a voice to a group that has too often been neglected in teacher education policy and research in Malta. Building an understanding of the professional role identities of VTEs is crucial and by exposition and recommendations, 
this research shows how this can be enhanced. This research will, therefore, influence policymakers in small states such as Malta to be cautious of uncritically taking on board concepts and policies from much larger geographical contexts, which may not be suited to the characteristics of micro-states such as Malta and from mainstream education contexts.

\section{Acknowledgments}

This article presents key findings from my doctoral research. The research was partially funded by the Tertiary Education Scholarship Scheme (TESS) Grant offered by the Maltese Ministry for Education and Employment.

\section{References}

Atkins, Liz. 2011. “A Guide to Instrumentalism: Initial Teacher Education in the Lifelong Learning Sector." 55th International Council on Education for Teaching World Assembly. Glasgow, Scotland.

Beijaard, Douwe, Nico Verloop, and Jan D. Vermunt. 2000. “Teachers' Perceptions of Professional Identity: An Exploratory Study from a Personal Knowledge Perspective." Teaching and Teacher Education 16(7):749-764.

Ben-Peretz, Miriam at al. 2010. "Education of Educators: Their Goals, Perceptions, and Practices." Professional Development in Education 36(1-2):111-129.

Benton, Ted and Ian Craib. 2001. Philosophy of Social Science: The Philosophical Foundations of Social Thought. 2nd ed. Basingstoke: Palgrave.

Berger, Peter L. and Thomas Luckmann. 1991. The Social Construction of Reality: A Treatise in the Sociology of Knowledge (No. 10). London: Penguin.

Bloomer, Martin and David James. 2003. "Educational Research in Educational Practice." Journal of Further and Higher Education 27(3):247-256.

Braun, Virginia and Victoria Clarke. 2006. "Using Thematic Analysis in Psychology." Qualitative Research in Psychology 3(2):77-101.

Braun, Virginia and Victoria Clarke. 2013. Successful Qualitative Research: A Practical Guide for Beginners. London: Sage Publications.

Bullough Jr., Robert V. 2005. "Being and Becoming a Mentor: School-Based Teacher Educators and Teacher Educator Identity." Teaching and Teacher Education 21:143-155.
Burke, Peter J. and Jan E. Stets. 2009. Identity Theory. New York: Oxford University Press.

Carter, Michael J. 2013. “Advancing Identity Theory: Examining the Relationship between Activated Identities and Behavior in Different Social Contexts." Social Psychology Quaterly 76(3):203-223.

CEDEFOP. 2017. Vocational Education and Training in Malta. Luxembourg: Publications Office of the European Union.

Cochran-Smith, Marilyn. 2003. "Learning and Unlearning: The Education of Teacher Educators." Teaching and Teacher Education 19(1):5-28.

Cort, Pia, Auli Harkonen, and Kristiina Volmari. 2004. PROFFProfessionalisation of VET Teachers for the Future. Luxembourg: Cedefop-The European Centre for the Development of Vocational Training.

Crawley, Jim. 2013. “"Endless Patience and a Strong Belief in What Makes a Good Teacher': Teacher Educators in Post-Compulsory Eduction in England and Their Professional Situation." Research in Post-Compulsory Education 18(4):336-347.

Danielewicz, Jane. 2001. Teaching Selves: Identity, Pedagogy, and Teacher Education. Albany, NY: State Univesity of New York Press.

Davison, Jon, Jean Murray, and Peter John. 2005. “Teacher Educators' Academic and Professional Identities: Faculty and Student Perspectives." 30th Annual Conference of the Association for Teacher Education in Europe. Amsterdam.

Dinkelman, Todd. 2011. "Forming a Teacher Educator Identity: Uncertain Standards, Practice, and Relationship." Journal 
of Education for Teaching: International Research and Pedagogy 37(3):309-323.

Drever, Eric. 1995. Using Semi-Structured Interviews in SmallScale Research: A Teacher's Guide. Cumbria: Scottish Council for Research in Education.

European Commission. 2013. Supporting Teacher Educators for Better Learning Outcomes. European Commission. Retrieved September 04, 2018 (http://ec.europa.eu/assets/eac/education/ policy/school/doc/support-teacher-educators_en.pdf).

Grollman, Philipp. 2008. “The Quality of Vocational Teachers: Teacher Education, Institutional Roles, and Professional Reality." European Educational Research Journal 7(4):537-547.

Hockings, Christine at al. 2009. "'I'm Neither Entertaining Nor Charismatic...' Negotiating Univerisity Teacher Identity within Diverse Student Groups." Teaching in Higher Education 14(5):483-494.

Izadinia, Mahsa. 2014. “Teacher Educators' Identity: A Review of Literature." European Journal of Teacher Education 37(4):426-441.

Kosnik, Clare and Clive Beck. 2008. "In the Shadows: Non-Tenure-Line Instructors in Pre-Service Teacher Education." European Journal of Teacher Education 31(2):185-202.

Livingston, Kay. 2014. “Teacher Educators: Hidden Professionals?" European Journal of Education 49(2):218-232.

Loughran, John. 2006. Devoloping a Pedagogy of Teacher Education: Understanding Teaching and Learning about Teaching. London: Taylor and Francis.

Lunenberg, Mieke and Mary Lynn Hamilton. 2008. “Threading a Golden Chain: An Attempt to Find Our Identities as Teacher Educators." Teacher Education Quarterly 35(1):185-205.

Lunenberg, Mieke, Fred Korthagen, and Anja Swennen. 2007. "The Teacher Educator as a Role Model." Teacher and Teacher Education 23:586-601.

McKeon, Frankie and Jennifer Harrison. 2010. “Developing Pedagogical Practice and Professional Identities of Beginning Teacher Educators." Professional Development in Education 28(1):25-44.

Menter, Ian et al. 2010. “Teacher Education Research in the UK: The State of the Art." Revue Suisse des Sciences de L'education 32(1):121-142.
Merriam, Sharan B. 1998. Qualitative Research and Case Study Applications in Education. Revised and Expanded from "Case Study Research in Education." San Francisco: Jossey-Bass.

Ministry for Education and Employment-Malta. 2016. My Journey: Achieving through Different Paths. Retrieved October 01, 2018 (http://www.myjourney.edu.mt/wp-content/uploads/2017/02/ MY-JOURNEY-BOOKLET-WEB-UPLOAD-24FEB17.pdf).

Misra, Pradeep K. 2011. "VET Teachers in Europe: Policies, Practices, and Challenges." Journal of Vocational Education and Training 63(1):27-45.

Murray, Jean. 2008. “Teacher Educators' Induction into Higher Education: Work-Based Learning in the Micro Communities of Teacher Education." European Journal of Teacher Education 31(2):117-133.

Murray, Jean. 2014. "Teacher Educators' Constructions of Professionalism: A Case Study." Asia-Pacific Journal of Teacher Education 42(1):7-21.

Murray, Jean and Trevor Male. 2005. "Becoming a Teacher Educator: Evidence from the Field." Teaching and Teacher Education 21(2):125-142.

Murray, Jean, Anja Swennen, and Leah Shagrir. 2008. “Understanding Teacher Educators' Work and Identities." Pp. 29-43 in Becoming a Teacher Educator, edited by A. Swennen and M. van der Klink. Netherlands: Springer.

Noel, Penny. 2006. "The Secret Life of Teacher Educators: Becoming a Teacher Educator in the Learning and Skills Sector." Journal of Vocational Education and Training 58(2):151-170.

Orr, Kevin and Robin Simmons. 2010. “Dual Identities: The In-Service Teacher Trainee Experience in the English Further Education Sector." Journal of Vocational Education and Training 62(1):75-88.

Powers, William. 1973. Behavior: The Control of Perception. Chicago: Aldine.

Said, Alison. 2018. "Vocational Teaching-Learning through the Eyes of Undergraduate Vocational Students in Malta: A Qualitative Exploratory Study." International Journal for Research in Vocational Education and Training (IJRVET) 5(1):42-63.

Springbett, Octavia. 2018. "The Professional Identities of Teacher Educators in Three Further Education Colleges: An Entanglement of Discourse and Practice." Journal of Education for Teaching 44(2):149-161. 
Stryker, Sheldon. 1980. Symbolic Interactionism: A Social Structural Version. Menlo Park, CA: Benjamin Cummings.

Stryker, Sheldon and Richard Serpe. 1994. "Identity Salience and Psychological Centrality: Equivalent, Overlapping, or Complementary Concepts?" Social Psychology Quarterly 57:16-35.

Swennen, Anja and Marcel van der Klink, eds. 2009. Becoming a Teacher Educator. Theory and Practice for Teacher Educators. Dordrecht: Springer.

Swennen, Anja, Ken Jones, and Monique Volman. 2010. “Teacher Educators: Their Identities, Sub-Identities, and Implications for Professional Development." Professional Development in Education 36(1-2):131-148.

Swennen, Anja, Monique Volman, and Mineke van Essen. 2008. "The Development of the Professional Identity of Two
Teacher Educators in the Context of Dutch Teacher Education." European Journal of Teacher Education 31(2):169-184.

Timmerman, Greetje. 2009. “Teacher Educators Modelling Their Teachers?" European Journal of Teacher Education 32(3):225238.

UOM. 2017. University of Malta. Retrieved October 01, 2019 (Faculty of Education, https://www.um.edu.mt/educ/mtl).

Vloet, Kara and Jacqueline van Swet. 2010. “'I Can Only Learn in Dialogue!' Exploring Professional Identities in Teacher Education." Professional Development in Education 36(1-2):149-168.

Williams, Judy, Jason K. Ritter, and Shawn M. Bullock. 2012. "Understanding the Complexity of Becoming a Teacher Educator: Experience, Belonging, and Practice within a Professional Learning Community." Studying Teacher Education 8(3):245-260.

\section{Citation}

Said, Alison. 2022. “Vocational Teacher Educators' Role Identity: A Case Study in Malta.” Qualitative Sociology Review 18(1):50-72.

Retrieved Month, Year (http://www.qualitativesociologyreview.org/ENG/archive_eng.php). DOI: https://doi.org/10.18778/1733-

8077.18.1.03 